\title{
Reversible Paired Helical Filament-Like Phosphorylation of Tau Is an Adaptive Process Associated with Neuronal Plasticity in Hibernating Animals
}

\author{
Thomas Arendt, ${ }^{1}$ Jens Stieler, ${ }^{1}$ Arjen M. Strijkstra, ${ }^{3}$ Roelof A. Hut, ${ }^{3}$ Jan Rüdiger, ${ }^{5}$ Eddy A. Van der Zee, ${ }^{3,4}$ \\ Tibor Harkany, ${ }^{4}$ Max Holzer, ${ }^{1}$ and Wolfgang Härtig ${ }^{2}$ \\ Departments of ${ }^{1}$ Neuroanatomy and ${ }^{2}$ Neurochemistry, Paul Flechsig Institute of Brain Research, University of Leipzig, D-04109 Leipzig, Germany, \\ Departments of ${ }^{3}$ Animal Behavior and ${ }^{4}$ Molecular Neurobiology, University of Groningen, 9757 NN Haren, The Netherlands, and ${ }^{5}$ Institute of Anatomy II, \\ Friedrich Schiller University Jena, D-07743 Jena, Germany
}

Neurofibrillary pathology [paired helical filaments (PHFs)] formed by the microtubule-associated protein tau in a hyperphosphorylated form is a major hallmark of Alzheimer's disease and related disorders. The process of tau phosphorylation, thought to be of critical importance for PHF formation, and its potential link to neurodegeneration, however, is not understood very well, mostly because of the lack of a physiological in vivo model of PHF-like tau phosphorylation. Here we describe the formation of highly phosphorylated tau, containing a number of PHF-like epitopes in torpor during hibernation. PHF-like phosphorylation of tau was not associated with fibril formation and was fully reversible after arousal. Distribution of PHF-like tau followed a consistent pattern, being most intense in the entorhinal cortex, hippocampus, and isocortical areas. Within the hippocampus, a particularly high labeling was seen in CA3 pyramidal cells. Somewhat lesser reactivity was present in CA1 neurons while dentate gyrus granule cells were not reactive. Formation of PHF-like tau in CA3 neurons was paralleled by the regression of synaptic contacts of the mossy fiber system terminating on CA3 apical dendrites. Mossy fiber afferentation was re-established during arousal, concomitantly with the decrease of PHF-like tau in CA3 neurons.

These findings implicate an essential link between neuronal plasticity and PHF-like phosphorylation of tau. The repeated formation and degradation of PHF-like tau might, thus, represent a physiological mechanism not necessarily associated with pathological effects. Hibernation will, therefore, be a valuable model to study the regulation of PHF-like tau-phosphorylation and its cell biological sequelae under physiological in vivo conditions.

Key words: Alzheimer's disease; hibernation; natural hypothermia; PHF; phosphorylation; plasticity; synapse; tau

\section{Introduction}

Formation of paired helical filaments (PHFs) is one of the critical neuropathological hallmarks of Alzheimer's disease (AD). Although the microtubule-associated protein tau in a hyperphosphorylated form has been established as primary constituent (Goedert et al. 1992b), the process of tau phosphorylation and its potential link to degeneration is not understood very well, mostly because of the lack of a physiological in vivo model of PHF-like tau phosphorylation. PHF formation in $\mathrm{AD}$ follows a hierarchical pattern of development throughout different cortical areas (Braak and Braak, 1991) that closely matches the pattern of neuronal plasticity in the adult brain (Arendt et al. 1998a). Brain areas that retain a high degree of structural plasticity in the adult

Received April 8, 2003; revised May 19, 2003; accepted May 22, 2003.

This work was supported by the Bundesministerium für Bildung, Forschung und Technologie, Interdisziplinäres Zentrum für Klinische Forschung at the University of Leipzig (01KS9504, Project (1) and the European Commission (QLK6-CT-1999-02112). We thank M. Goedert and R. Jakes (Cambridge, UK) and P. Davies (Albert Einstein College of Medicine, Bronx, NY) for generously providing tau antibodies and recombinant tau protein and Mrs. Ute Bauer for her excellent technical assistance.

Correspondence should be addressed to Dr. Thomas Arendt, Paul Flechsig Institute of Brain Research, Department of Neuroanatomy, Jahnallee 59, D-04109 Leipzig, Germany. E-mail: aret@medizin.uni-leipzig.de. Copyright $\odot 2003$ Society for Neuroscience $\quad$ 0270-6474/03/236972-10\$15.00/0 are most early and most severely affected. Failures of synaptic plasticity are, thus, assumed to represent early events in the course of AD (Ashford and Jarvik, 1985; Cotman and Anderson, 1988; Flood and Coleman, 1990; Geddes and Cotman, 1991; Swaab, 1991; Mesulam, 1999) that eventually lead to alteration of tau phosphorylation. The potential link between synaptic plasticity, synaptic detachment, and the regulation of tau phosphorylation, however, has not been addressed directly under physiological in vivo conditions.

In the present study, we have used the hibernation cycle, a physiological model of adaptation associated with an extraordinary high degree of structural neuronal plasticity, to analyze the potential relationship between synaptic plasticity and alterations in tau phosphorylation. It has been shown previously, that during torpor, a natural state of hypothermia, synaptic contacts between mossy fibers and hippocampal pyramidal neurons undergo dramatic regressive changes that are fully reversible very rapidly during euthermy (Popov and Bocharova, 1992; Popov et al., 1992). Here, we demonstrate that this rapid, reversible, and repeated regression of synaptic and dendritic components on CA3 neurons is associated with a reversible PHF-like phosphorylation of tau at a similar time course. These findings implicate an essential 
link between neuronal plasticity and PHF-like phosphorylation of tau, one of the major hallmarks of AD. Hibernation will, thus, represent a model to study the regulation of PHF-like tau phosphorylation and its cell biological sequelae under physiological in vivo conditions.

\section{Materials and Methods}

Animals. The 36 adult European ground squirrels (Spermophilus citellus) used in this study were either captured from a dense population near Vienna (Millesi et al., 2001), born in the laboratory from females that were caught pregnant, or bred in outdoor enclosures in Haren, The Netherlands (Hut et al. 2002a). The animals were kept in Lucite cages (length $\times$ width $\times$ height $=48 \times 28 \times 50 \mathrm{~cm}$ ) with a wooden nestbox attached $(15 \times 15 \times 15 \mathrm{~cm})$. Wood shavings were used as bedding material, and food (rabbit breeding chow, Teurlings, Waalwijk, The Netherlands) and water were supplied ad libitum. The animals were kept in a climate-controlled room at a relative humidity of $60 \%$ throughout the experiment. Hibernation was induced by gradually lowering ambient temperature from 20 to $7^{\circ} \mathrm{C}$ and changing light conditions from a $12 \mathrm{hr}$ light/dark cycle to continuous dim red light ( $<1$ lux) in autumn. Individual torpor-arousal patterns were assessed by measuring nestbox temperatures every minute with a computer-based recording system or by recording outside nestbox activity (Oklejewicz et al., 2001; Hut et al., $2002 b)$. Registration of torpor-arousal patterns was validated by using customized abdominal temperature loggers (Tidbit; Onset; Hut et al. 2002a,b) that registered body temperature every $48 \mathrm{~min}$. This study was approved by the Animal Experiments Committee of the University of Groningen (BG02198).

Experimental design. In total, 36 animals were studied, 32 for immunohistochemistry and an additional 4 for Western blotting. The animals were killed in four different stages within the torpor and arousal periods in hibernation: torpor short (TS; $n=6$ ), torpor long (TL; $n=6$ ), arousal short (AS; $n=6)$, and arousal long (AL; $n=7)$. Eleven animals were killed after becoming continuously euthermic after hibernation (EU; $n=$ 11). Hibernating animals showed hypothermic periods of $11.01 \pm 0.18 \mathrm{~d}$ (mean \pm SEM) and euthermic periods (including arousal) of $21.13 \pm$ $0.38 \mathrm{hr}$ before killing. Brain material of the hibernating animals was collected after $1.53 \pm 0.06 \mathrm{hr}(\mathrm{AS}), 8.27 \pm 0.05 \mathrm{hr}(\mathrm{AL}), 2.34 \pm 0.21 \mathrm{~d}$ (TS), and $7.11 \pm 0.1 \mathrm{~d}(\mathrm{TL})$ after the onset of the previous (final) arousal to euthermy. Body temperatures after start of perfusion confirmed that the groups represented the specific phases of hibernation: rectal temperatures were $30.9 \pm 1.6^{\circ} \mathrm{C}(\mathrm{AS}), 34.5 \pm 0.3^{\circ} \mathrm{C}(\mathrm{AL}), 9.8 \pm 1.5^{\circ} \mathrm{C}(\mathrm{TS})$, and $8.21 \pm 0.3^{\circ} \mathrm{C}(\mathrm{TL})$. Arousal was induced by gentle handling at room temperature for 3-5 min. Arousal induction was performed at least 10 weeks after onset of hibernation. At the time of brain material collection, the duration of the previously experienced torpor phase did not differ between the groups.

Brain material of nonhibernating animals (EU) was collected $6-7 \mathrm{~d}$ after cessation of hibernation, initiated by an increase in ambient temperature from 7 to $25^{\circ} \mathrm{C}$ in early spring (Hut et al., 2002b). Body temperature after start of perfusion was $36.5 \pm 0.4^{\circ} \mathrm{C}$ (mean $\pm \mathrm{SEM}$ ). All animals were killed with $2 \mathrm{ml}$ of $6 \%$ pentobarbital 10 min before perfusion (immunohistochemistry, electron microscopy) or decapitation (Western blotting).

Immunohistochemistry. Animals were transcardially perfused with $4 \%$ paraformaldehyde in phosphate buffer. Brains were equilibrated with $30 \%$ sucrose in phosphate buffer and cut coronally on a freezing microtome into $25 \mu \mathrm{m}$ sections. Series of free-floating sections from 32 animals of all groups (five to six animals per group) were applied to the immunoperoxidase labeling of PHF-like phosphorylated tau protein (AT8, 1:2000; Innogenetics, Zwijndrecht, Belgium), MAP2 (mouse clone HM-2; 1:1000; Sigma, Taufkirchen, Germany), PSA-NCAM (mouse clone 2-2B; 1:500; AbCys S.A., Paris, France), and synaptophysin (rabbit; 1:1600; Dako, Hamburg, Germany).

In brief, all sections were processed with a streptavidin-biotin technique and nickel-enhanced diaminobenzidine as chromogen as previously described (Härtig et al., 1995). For double immunofluorescence of AT8 staining and MAP2, sections were incubated overnight with a mix- ture of AT8 (1:400) and rabbit anti-MAP2 (1:250; Chemicon, Temecula, CA). Immunoreactivities were visualized with a cocktail consisting of Cy3-conjugated goat anti-mouse IgG and Cy2-tagged goat anti-rabbit IgG (Dianova, Hamburg, Germany). Controls were performed by omitting the primary antibodies resulting in the absence of any cellular staining.

Relative strength of immunoreactivity in the hippocampal stratum lucidum (PSA-NCAM, synaptophysin, MAP2) and over somata of CA3 pyramidal neurons (AT8) was comparatively determined by densitometric measurements on sections processed in parallel with nickel-enhanced diaminobenzidine. Ten regions of interest $(50 \times 50 \mu \mathrm{m})$ were randomly selected for each section, and the optical density, corrected for background, was obtained using the image processing and analyzing system analySIS (Münster, Germany) connected to a xrs camera (SL Microtest, Jena, Germany) attached to a Zeiss Axiophot microscope. Five sections were analyzed for each animal (group size: $n=5$ or 6 animals).

Electron microscopy. For electron microscopy, animals were transcardially perfused with $0.1 \mathrm{M}$ PBS, followed by $300 \mathrm{ml}$ of ice-cold fixative containing $4 \%$ paraformaldehyde and $2.5 \%$ glutaraldehyde in $0.1 \mathrm{M}$ PBS, $\mathrm{pH}$ 7.4. After postfixation in the same solution overnight $\left(4^{\circ} \mathrm{C}\right), 70 \mu \mathrm{m}$ vibratome sections were made (Vibratome series 1000), rinsed in cacodylic buffer, $\mathrm{pH} 7.2$, and subsequently postfixed for $2 \mathrm{hr}$ at room temperature with $1 \% \mathrm{OsO}_{4}$ in $0.1 \mathrm{M}$ cacodylic buffer, $\mathrm{pH}$ 7.2. After a short washing in aqua bidest, tissue was dehydrated in a graded ethanol series (30, 50, 70, and $90 \%$ each $10 \mathrm{~min}, 100 \% \times 2$, each $60 \mathrm{~min}, 100 \%$ propylene oxide $2 \times$, each $7 \mathrm{~min}$ ). Dehydrated sections were finally embedded in Epon 812 following routine procedures and cured for $48 \mathrm{hr}$ at $60^{\circ} \mathrm{C}$. Pieces of layer $\mathrm{V}$ prefrontal cortex were excised, and ultrathin sections cut on a Reichert Ultracut $S$ were contrasted for 20 min with 5\% uranyl acetate in aqua bidest. and $2 \mathrm{~min}$ in Reynolds lead citrate. Sections were examined with a Zeiss (Oberkochen, Germany) EM 912 electron microscope.

Western blotting. Fresh brain material of four animals was collected for Western blotting. Three animals were hibernating, two matching the time that the AL group were killed ( $>7 \mathrm{hr}$ after arousal induction, after $>7 \mathrm{~d}$ of torpor) and one matching the time that the TL group were killed ( $>7 \mathrm{~d}$ of torpor). The fourth animal was killed during continuous euthermy in summer (EU group).

The animals were killed with $2 \mathrm{ml}$ of $6 \%$ pentobarbital and decapitated. Brains were removed immediately and submerged in ice-cold PBS. Neocortex and hippocampus were dissected and homogenized in lysis buffer [20 mм Tris-HCl, pH 7.2, 2 mм $\mathrm{MgCl}_{2}, 100 \mathrm{~mm} \mathrm{NaCl}, 5 \mathrm{~mm} \mathrm{NaF}$, $1 \mathrm{~mm} \mathrm{Na}_{3} \mathrm{VO}_{4}, 0,5 \%$ NP-40, $1 \mathrm{~mm}$ DTT, $100 \mu \mathrm{g} / \mathrm{ml} \mathrm{PMSF}, 2 \mu \mathrm{g} / \mathrm{ml}$ Leupeptin, $2 \mu \mathrm{g} / \mathrm{ml}$ Pepstatin A, and $600 \mathrm{~nm}$ okadaic acid (Sigma); ratio tissue to buffer: 1:5]. After centrifugation $\left(5000 \times g, 30 \mathrm{~min}, 4^{\circ} \mathrm{C}\right)$, lysates were filled up with glycerol to a concentration of $50 \%(\mathrm{v} / \mathrm{v})$. Protein contents were determined by the Bradford assay. Proteins were separated on 10 or $5 \%$ to $15 \%$ gradient SDS polyacrylamide gels using $30 \mu \mathrm{g}$ of total protein per well and subsequently transferred to a polyvinylidene difluoride (PVDF) transfer membrane (PolyScreen; PerkinElmer Life Sciences, Boston, MA). Membranes were washed once in PBS, blocked in PBS containing $2 \%$ BSA (w/v), and probed with mouse anti-MAP2 (1: $1000)$ or rabbit anti-synaptophysin (1:5000). PHF-like phosphorylated tau was detected by the following mouse monoclonal antibodies (numbering of amino acid residues based on the 441 amino acids of human tau) (Goedert et al. 1989a): AT8 (Ser202/Thr205; 1:1000; Innogenetics, Zwijndrecht, Belgium); AT100 (Ser212/Thr214; 1:1000; Innogenetics), AT180 (Thr231; 1:1000; Innogenetics), AT270 (Thr181; 1:1000; Innogenetics), PHF-1 (Ser396/Ser404; 1:2000; courtesy of P. Davies, Albert Einstein College of Medicine, Bronx, NY) and 12E8 (Ser262/Ser365; 1:1000, Athena Neuroscience). The mouse monoclonal antibody Tau-1 (1:2000; Chemicon) detects tau when unphosphorylated at Ser198, Ser199, Ser202. The polyclonal anti-tau antibodies BR134 (1:1000, courtesy of M. Goedert, Cambridge, UK) and anti-tau (1:1000; Sigma) were used for phosphorylation-independent detection of tau. Detection of bound primary antibodies was performed with biotinylated sheep anti-mouse or donkey anti-rabbit secondary antibodies (1:2000; Amersham Pharmacia, Freiburg, Germany) and the ExtrAvidin-peroxidase conjugate (1:5000; 
Sigma). Blots were developed with Super Signal West Pico ECL-System (Pierce, Rockford, IL) and subsequently with diaminobenzidine- $\mathrm{H}_{2} \mathrm{O}_{2}$.

To define the pattern of isoforms, tau was treated with alkaline phosphatase (Goedert et al., 1989a). Brain extracts dialyzed against TBS, $\mathrm{pH}$ 8.0, $1 \mathrm{~mm} \mathrm{MgCl} 2,1 \mathrm{~mm}$ PMSF, and $1 \mu \mathrm{g} / \mathrm{ml}$ leupeptin were boiled for 10 min followed by centrifugation at $13,000 \times g, 4^{\circ} \mathrm{C}$ for $10 \mathrm{~min}$. Ammonium sulfate was added to the supernatant to a $50 \%$ saturation. Precipitated proteins were centrifuged for $30 \mathrm{~min}$ at $100,000 \times g$ at $4^{\circ} \mathrm{C}$. Floating protein pellet was dissolved in $100 \mu \mathrm{l}$ of phosphatase buffer, $20 \mathrm{~mm}$ Tris- $\mathrm{HCl}, \mathrm{pH}$ 8.0, $1 \mathrm{~mm} \mathrm{MgCl} 2,1 \mathrm{~mm}$ PMSF, and $1 \mu \mathrm{g} / \mathrm{ml}$ leupeptin and treated with $0.2 \mathrm{U}$ of alkaline phosphatase (Sigma, P-4069) for $3 \mathrm{hr}$ at $65^{\circ} \mathrm{C}$. After adding fourfold concentrated SDS sample buffer, proteins and a mix of six recombinant human tau isoforms (courtesy of R. Jakes, Cambridge, UK) were separated on 9\% SDS polyacrylamide gels and probed as described above using BR134 at 1:2000 dilution.

RNA preparation, reverse transcription, and cloning of tau cDNA from ground squirrel. RNA was extracted from cerebellum using Trizol (Invitrogen) and was oligo(dT)-primed reverse-transcribed using Superscript Reverse Transcriptase (Invitrogen, Karlsruhe, Germany). A PCR product in the range of 1300-1500 bp was generated using first strand DNA and forward primer TMF (CTC CCG TCC TCG CCT CTG TCG ACT ATC AGG) and reverse primer TJR (TGA TCA CAA ACC CTG CTT GG) in a PCR reaction using a mixture of Taq MasterMix (Qiagen, Hilden, Germany) and Pfu Turbo Polymerase (Stratagene, Amsterdam, The Netherlands). The cycling profile consists of an initial denaturation step $3 \mathrm{~min}$ at $94^{\circ} \mathrm{C}$ followed by denaturation $20 \mathrm{sec} 94^{\circ} \mathrm{C}$, annealing $30 \mathrm{sec}$ $60^{\circ} \mathrm{C}$, and elongation $90 \sec 72^{\circ} \mathrm{C}$ repeated 35 times and a final elongation step $7 \mathrm{~min} 72^{\circ} \mathrm{C}$. The PCR product was gel-extracted and ligated blunt into cloning vector $\mathrm{pZErO}-2$ (Invitrogen). Clones containing insert were screened by colony-PCR, and the longest, most abundant, tau isoform cDNA was sequenced. The cDNA sequence was translated into amino acid sequence and was aligned with rat and human tau amino acid sequence using ClustalW program (www.ebi.ac.uk/clustalw) (Thompson et al., 1994). The cladogram was obtained by multiple sequence alignments using ClustalW (option ignore gaps $=$ on) using the following tau protein sequences: human, NM 005910; mouse, AAA58343; rat, M84156 (exon 4a and exon 6 were omitted); macaque, P57786; baboon, Q9MYX8; goat, O02828; and bovine, NP 776531.

The relative abundance of four-repeat to three-repeat tau isoforms was determined by RT-PCR using forward primer TJF (GGC TAC AGC AGC CCC GGC TC) and reverse primer TJR. The cycling profile consists of an initial denaturation step $5 \mathrm{~min}$ at $94^{\circ} \mathrm{C}$ followed by denaturation $30 \mathrm{sec}$ $94^{\circ} \mathrm{C}$, annealing $40 \mathrm{sec} 58^{\circ} \mathrm{C}$, elongation $45 \mathrm{sec} 72^{\circ} \mathrm{C}$ repeated 35 times, and a final elongation step $7 \mathrm{~min} 72^{\circ} \mathrm{C}$. PCR products were separated in a $1.5 \%$ agarose gel and stained with ethidium bromide.

\section{Results}

Hibernation induces PHF-like phosphorylation of tau

Effects of hibernation on the phosphorylation stage of tau were analyzed by Western blotting of cortical and hippocampal extracts and immunohistochemistry. A mobility shift of tau was observed after the transition from euthermy to torpor, as visualized by the phosphorylation-independent detection of tau with the antibody BR134 (Fig. 1). In the euthermic ground squirrels, this antibody detects bands at 68,70 , and $72 \mathrm{kDa}$. During torpor, the $68 \mathrm{kDa}$ band is greatly diminished with the appearance of immunoreactive bands of $>72 \mathrm{kDa}$. This mobility shift is accompanied by an enhancement of immunoreactivity for all phosphorylation-dependent antibodies tested, detecting six distinct PHF-like phosphoepitopes on tau (AT8, AT 100, AT180, AT270, PHF-1, and 12E8). Thus, phosphorylation of serines corresponding on the longest isoform of human to amino acids 198, $199,202,212,262,365,396,404$, and of threonines 181, 205, 214, 231 becomes highly enhanced in the hibernation cycle during torpor, indicating a large increase in tau phosphorylation. These findings were corroborated by a diminished reactivity of the 68

\section{neocortex hippocampus \\ EU TL AL EU TL AL}

BR134

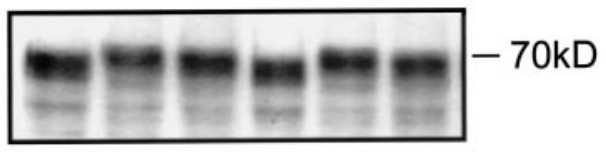

AT8

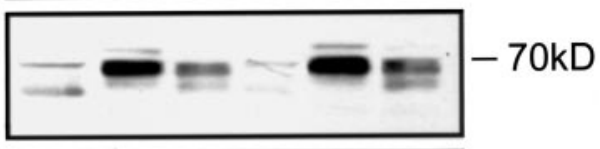

AT100

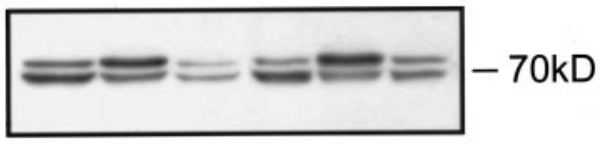

AT180

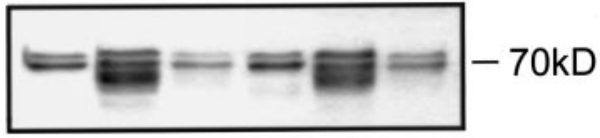

AT270

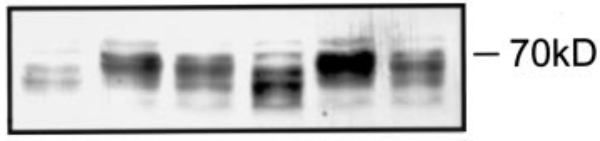

PHF-1

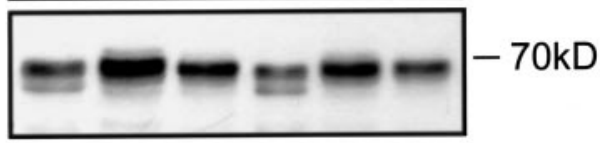

12E8

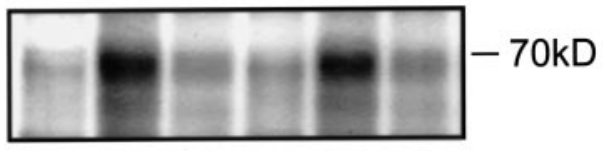

Tau-1

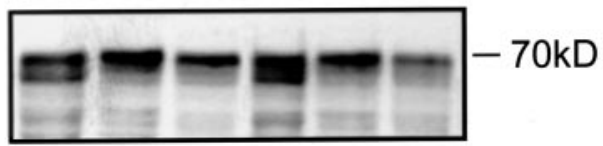

Figure 1. Phosphorylation of tau protein in the neocortex and hippocampus in an euthermic animal (EU), in long torpor (TL), and after long arousal (AL). Immunoblots were reacted for phosphorylation-independent detection of tau (BR134), specific PHF-like tau-phosphoepitopes (AT8, AT100, AT180, AT270, PHF-1, 12E8) and tau, unphosphorylated at Ser198, Ser199, and Ser202 (Tau-1).

$\mathrm{kDa}$ band by Tau-1, which detects tau when dephosphorylated on Ser199/Ser202.

After enzymatical dephosphorylation, a pattern of five isoforms was resolved (Fig. 2). The strongest BR134immunoreactive band is the tau isoform with the lowest electrophoretic mobility in the ground squirrel and aligns with human recombinant tau isoform comprising exon 2 and exon 3. Presumably this band represents the longest ground squirrel tau isoform containing exon 2, 3, and 10 because rodent tau isoforms are shorter than corresponding human isoforms, and in adult rodent brains this isoform is most abundant. The pattern of isoforms and their relative expression levels were unaffected during the hibernation cycle.

To identify and assign the major ground squirrel tau isoform on Western Blot we cloned and sequenced the most abundant tau cDNA. This cDNA corresponds to the longest human isoform containing exon 2,3 and exon 10. The ground squirrel amino acids sequence has two deletions in exon 1, a 11 amino acid deletion, which is typical for rodent tau sequences and a unique 2 amino acid deletion. This explains the faster electrophoretic mobility of the longest tau protein isoform after dephosphorylation in squirrel compared with human. RT-PCR of a tau cDNA fragment comprising exon 10 shows a more prominent occurrence of exon 10 containing tau mRNA in ground squirrel brain than in 


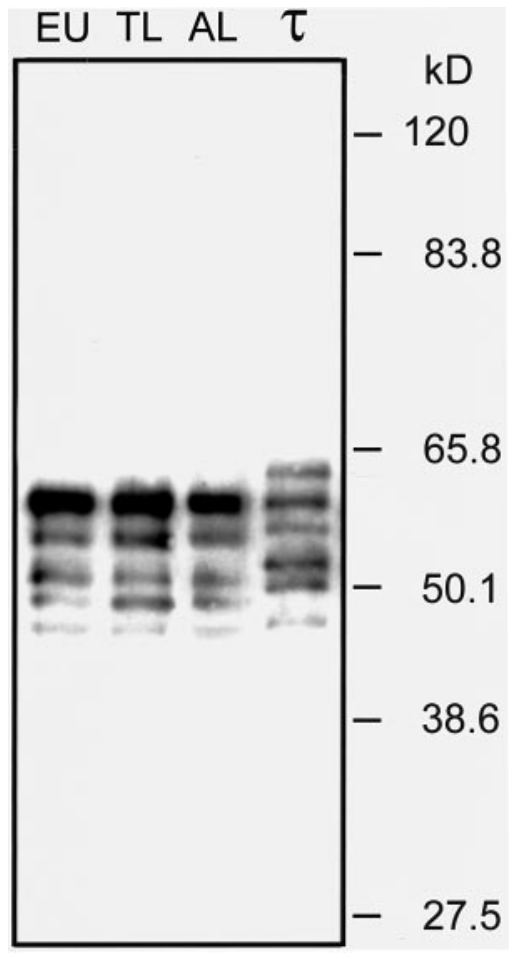

Figure 2. Tau protein isoform expression in hibernating and euthermic animals. Heatstable brain extracts from euthermic (EU), torpor (TL), and aroused (AL) animals were dephosphorylated with alkaline phosphatase and probed with anti-tau C-terminal antibody BR134. For comparison of the relative electrophoretic mobility, a mixture of the six recombinant human $(\tau)$ isoforms was run in parallel. No obvious change in isoform composition is apparent during the hibernation cycle.

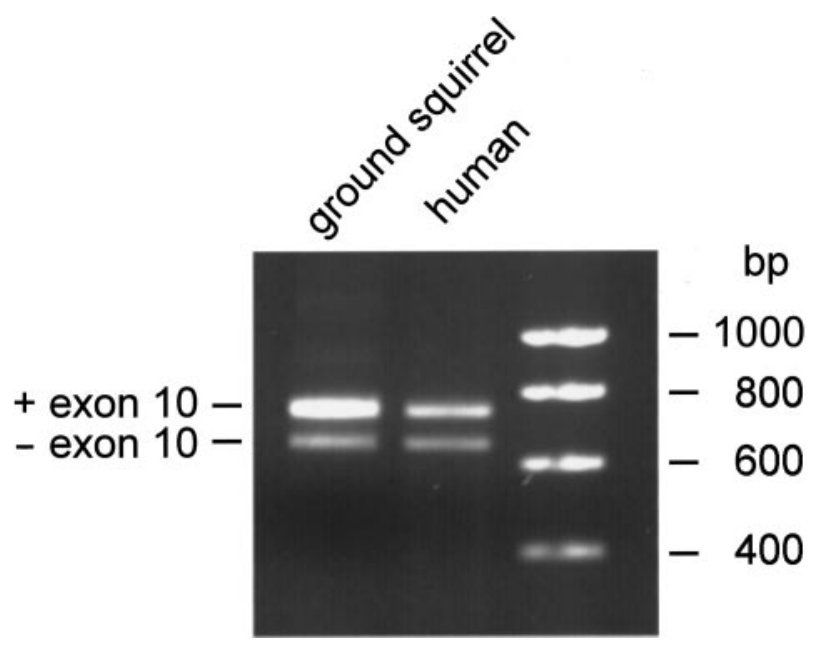

Figure 3. Relative expression levels of tau isoforms containing exon 10 and isoforms lacking exon 10. RT-PCR of a tau fragment comprising exon 10. Brains of ground squirrel contain a higher relative proportion of exon 10 containing tau mRNAs compared with human brain.

human brain (Fig. 3). The cladogram derived from comparison of tau protein sequences of different mammals shows that the deducted amino acid sequence of ground squirrel has strongest similarities to rodents like mice and rats but has also similarities to human sequence (Fig. 4). To simplify the analysis we compared variable amino acids in ground squirrel sequence to human and rat sequence only. We found 14 amino acid substitutions and one gap of 11 amino acids, which are identical between ground squirrel and rat, whereas 19 amino acids are alike between ground squirrel and human, and another 17 amino acids and a two amino acid gap are unique for ground squirrel.

Furthermore, the amino acid sequence shows that the epitopes of phosphorylation-dependent and independent antibodies used to label tau protein in ground squirrel are sufficiently conserved.

When the distribution of phospho-tau was analyzed immunohistochemically, strongest reactivity for AT8 was found in the ventral hippocampus, entorhinal cortex, and isocortex (Fig. 5). A particularly high labeling was seen in hippocampal CA3 pyramidal cells. To a lesser extent reactivity was also present in CA1 pyramidal neurons, whereas dentate gyrus granule neurons were not reactive (Fig. 6). Marked labeling was also seen in subcortical areas, in particular in hypothalamic and epithalamic nuclei, whereas thalamic nuclei were only marginally reactive.

Both Congo red and thioflavin S staining for the detection of fibrillar aggregates were negative. Electron microscopic investigation of the cortex from torpoid animals did not reveal any evidence for the formation of neurofibrillary aggregations within the dendritic compartment (Fig. 7).

\section{Reversibility of tau phosphorylation after arousal}

Reversibility of tau phosphorylation was of particular interest in the present paradigm, because incomplete reversibility would likely result in the formation of PHFs. As seen on Western blots (Fig. 1) and immunohistochemical preparations (Figs. 5, 6), increased tau phosphorylation was fully reversible after arousal. Already a few hours after animals were awake, a reversibility of the mobility shift of tau, associated with a diminished reactivity for all phosphorylation-dependent anti-tau antibodies, was observed (Fig. 1).

The process of reversible generation of phospho-tau epitopes and their subcellular distribution was analyzed in more detail in the hippocampus (Fig. 6). Immunoreactivity for AT8 was typically found in the somatodendritic compartment of CA3 pyramidal neurons and to a lesser extent also in CA1 and CA4 neurons, where it developed gradually. At shorter periods of torpor, labeling with AT8 became first detectable in the apical dendrite of pyramidal cells while the perikarya were still devoid of reactivity (Fig. 6F, $F^{\prime}$ ). Conversely, after arousal, immunoreactivity first disappeared in the perikarya, whereas it remained somewhat longer in dendrites (Fig. 6G, $G^{\prime}$ ). Reactivity for any phosphorylation-dependent antibody used in the study completely disappeared after longer periods of arousal (Fig. $6 H, H^{\prime}$ ).

\section{PHF-like phosphorylation-dephosphorylation of tau in the hibernation cycle is synchronized with a regression-re-establishment of afferentation}

Cellular and subcellular pattern of phosphorylated tau present under the condition of torpor might be of particular relevance to the process of neuronal connectivity and plasticity. This relationship was specified further in the hippocampal mossy fiber system that reproducibly underwent cyclic changes during hibernation (Popov and Bocharova, 1992; Popov et al., 1992; Hut et al., 2001). The mossy fiber system arises in the dentate gyrus granule cells that remained completely devoid of AT8 reactivity during the whole hibernation cycle and terminates in the stratum lucidum on apical dendrites of CA3 pyramidal cells. The latter displayed a high AT8 reactivity during torpor.

As shown in the present study, the mossy fiber system can be identified by the presence of PSA-NCAM that in ground squirrels is not restricted to developmental stages but persists in the adult euthermic animal. During torpor, expression of PSA-NCAM dis- 
appears almost completely with the exception of a few granule cells (Fig. 8A1,A2). After arousal, PSA-NCAM expression in the mossy fiber system gradually reappears (Fig. 8A3,A4). Correspondingly, immunoreactivity for synaptophysin in the CA3stratum lucidum, where the mossy fibers contact CA3 apical dendrites disappears and reappears with the hibernation cycle (Figs. 6B, 7). Cyclic changes of synaptophysin immunoreactivity were also found by Strijkstra et al. (2003) based on a monoclonal antibody (Hut et al., 2001). These periodic changes during the cycle in presynaptic PSA-NCAM and synaptophysin are synchronized with the disappearance and reappearance of postsynaptic microtubule-associated protein (MAP2) in CA3 cells (Figs. 8C, 9), as reported by Hut et al. (2001). Our findings indicate a gradual regression of mossy fiber synapses and corresponding postsynaptic elements during torpor, associated with the accumulation of phosphorylated tau at postsynaptic sites, which completely reverses after arousal.

A synopsis of the synchronized changes in presynaptic and postsynaptic makers and phosphorylated tau obtained during the hibernation cycle on immunohistochemical preparations is displayed in Figure 10. In parallel with synaptic regression on CA3 cells, the accumulation of phosphorylated tau develops, reaching highest amounts during deep torpor. Highly phosphorylated tau decreases again during arousal and eventually disappears parallel to the process of re-expression of synaptophysin and MAP2.

\section{Discussion}

One of the first who clearly recognized the plasticity-related nature of Alzheimer pathology was Ramón y Cajal (1928). He also was the first who tried to mimic the pathology of $\mathrm{AD}$, putting research on this disorder on an experimental basis. Among his pupils he prompted a number of studies intending to analyze sequelae of a disturbed metabolism induced by manipulations such as hibernation (Ramón y Cajal, 1904; Tello, 1904), starvation, and exposure to cold (Donaggio, 1906), combined with thyroidectomy or parathyroidectomy (Balli, 1906; Lewy, 1923; Rasdolsky, 1926; Alexander, 1934; Stern and Elliott, 1949). Even if these early studies failed to reproduce true neurofibrillary degeneration of $\mathrm{AD}$, they were able to induce some kind of neurofibrillary changes (Balli, 1906; Donaggio, 1906; Lewy, 1923; Rasdolsky, 1926) associated with argentophily (Ramón y Cajal, 1904; Tello, 1904; Rasdolsky, 1926). In the light of more recent data on thyroid disease as a potential risk factor for AD (Kalmijn et al., 2000) and on the effects of starvation on tau phosphorylation (Yanagisawa et al., 1999; Planel et al., 2001), we re-evaluated a potential link between the hibernation cycle and neurofibrillary

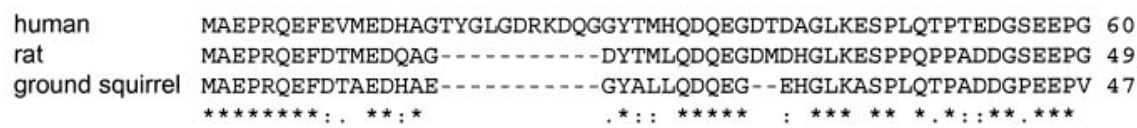

human SETSDAKSTPTAEDVTAPLVDEGAPGKQAAAQPHTEIPEGTTAEEAGIGDTPSLEDEAAG 120 rat SETSDAKSTPTAEDVTAPLVEERAPDKQATAQSHTEIPEGTTAEEAGIGDTPNMEDQAAG 109 ground squirrel SETSDAKSTPTAEDVTAPLVDERTPGEQAATQPPTDIPEGTTAEEAGIGDTPNMEDQAAG 107

human HVTQARMVSKSKDGTGSDDKKAKGADGKT - -KIATPRGAAPPGQKGQANATRIPAKTPPA 178 rat HVTQARVAGVSKDRTGNDEKKAKGADGKTGAKIATPRGAATPGQKGTSNATRIPAKTTPS 169 ground squirrel HVTQARMVSKGKEGTGSEDRKAKGADSKTGTKIATPRGTAPPGQKGTANATRIPAKTTPS 167

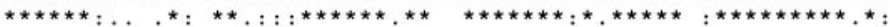

human PKTPPSSGEPRSGDRSGYSSPGSPGTPGSRSRTPSLPTPPTREPKKVAVVRTPPKSPSS 238 rat PKTPPGSGEPPKSGERSGYSSPGSPGTPGSRSRTPSLPTPPTREPKKVAVVRTPPKSPSA 229

human AKSRLQTAPVPMPDLKNVKSKIGSTENLKHQPGGGKVQI INKKLDLSNVQSKCGSKDNIK 298 rat SKSRLQTAPVPMPDLKNVRSKIGSTENLKHQPGGGKVQI INKKLDLSNVQSKCGSKDNIK 289

human HVPGGGSVIVYKPVDLSKVTSKCGSLGNIHHKPGGGQVEVKSEKLDFKDRVQSKIGSLD 358 rat HVPGGGSVQIVYKPVDLSKVTSKCGSLGNIHHKPGGGQVEVKSEKLDFKDRVQSKIGSLD 349

ground squirrel HVPGGGSVQIVYKPVDLSKVTSKCGSLGNIHHKPGGGQVEVKSEKLDFKDRVQSKIGSLD 347

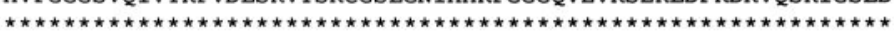

human NITHVPGGGNKKIETHKLTFRENAKAKTDHGAEIVYKSPVVSGDTSPRHLSNVSSTGSID 418 rat NITHVPGGGNKKIETHKLTFRENAKAKTDHGAEIVYKSPVVSGDTSPRHLSNVSSTGSID 409 NITHVPGGGNKKIETHKLTFRENAKAKTDHGAEIVYKSPVVSGDTSPRHLSNVSSTGSIN 407

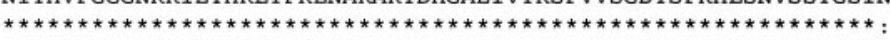

human MVDPQLATLADEVSASLAKQGL 441

rat MVDSPLATLADEVSASLAKQGL 432

MVDSPQLATLADEVSASLAKQGL 430

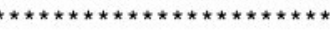

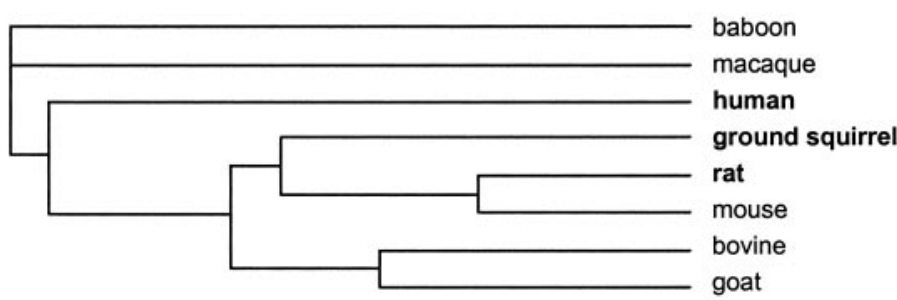

Figure 4. Sequenz homology of tau in ground squirrel, rat, and human. Top, Alignment of amino acid sequence deduced from the cDNA sequence of the longest, most abundant tau isoform of ground squirrel with rat and human tau amino acid sequence (ClustalW program). Bottom, The cladogram, obtained by multiple sequence alignments using ClustalW, places ground squirrel tau in the group of rodent where it is most closely related to human.

pathology made up by a hyperphosphorylated form of the microtubule-associated protein tau.

Hibernation is a behavioral strategy used by several mammalian species to minimize energy expenditure under inhospitable environmental conditions. During hibernation, overall metabolic rate as well as heart and respiratory rate are greatly reduced (Wang, 1978; Geiser and Kenagy, 1988), by tolerating a body temperature near the ambient temperature in a regulated hypothermic state. Low metabolic rate during torpor is accompanied by dramatically reduced neuronal functions. EEG measurements of torpid hibernators have shown that almost no brain activity is present (Walker et al., 1977; Krilowicz et al., 1988; Daan et al., 1991). Correspondingly, hibernation elicits negative effects on memory retention in conditioned tasks (Millesi et al., 2001). It was hypothesized that because of these potentially deleterious effects, hibernators interrupt the torpor state regularly to return 


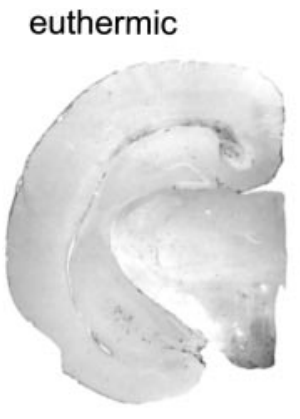

torpor

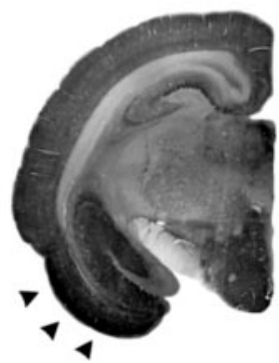

arousal

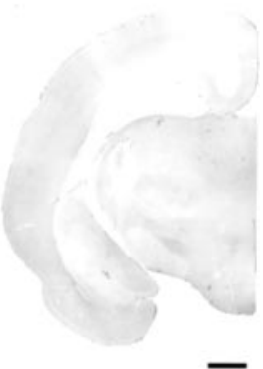

Figure 5. Immunohistochemical detection of PHF-like phosphorylated tau by the monoclonal antibody AT8 in long torpor (middle) as compared with a non-hibernating euthermic animal (left) and an animal after long arousal (right). Note the strong reactivity in the entorhinal cortex (arrowheads), hippocampus, cortex, as well as hypothalamic and epithalamic nuclei in torpor and its complete reversal within hours after arousal. Scale bar, $1 \mathrm{~mm}$.

to euthermy (Strijkstra and Daan, 1998). These regularly occurring euthermic phases, called "arousal episodes", are apparently necessary to protect against mechanisms that otherwise would lead to complete memory loss. They last $4-24 \mathrm{hr}$, depending on species and size (French, 1985). Arousals, however, are expensive in terms of energy (Wang, 1978, 1989; Kenagy et al., 1989). The adaptive significance of the hibernation cycle makes this an ideal model to investigate cellular sequelae of neuroplasticity and its potential association with the phosphorylation state of tau in a physiological setting.

During torpor, when brain temperature decreases to $<15^{\circ} \mathrm{C}$, electroencephalographic activity is strongly reduced (Krilowicz et al., 1988; Strijkstra et al., 1999; Gabriel et al., 1998). Because activity is a measure of use and neuronal connections remain functional through regular use, this decrease may negatively affect the maintenance of neuronal connections (Kavanau, 1997). Evidence for a reduced neuronal connectivity during the hibernation cycle has been provided for different brain regions in a variety of hibernating animals (Malinsky and Malinska, 1975, 1988; Malinsky, 1983; Malinsky and Polach, 1985; Popov and Bocharova, 1992; Strijkstra and Daan, 1997; Hut et al., 2002b). A cycle of synaptic
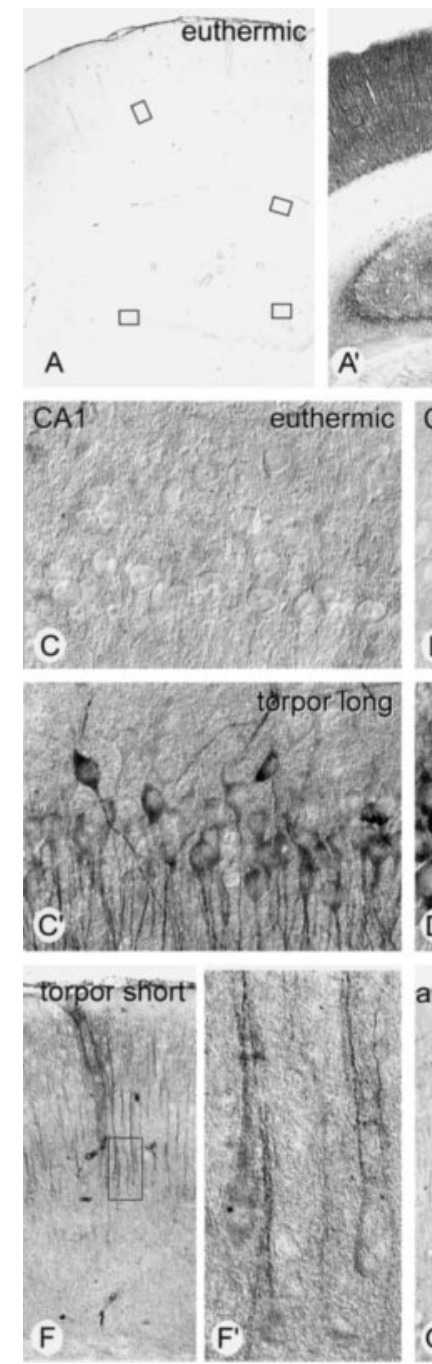
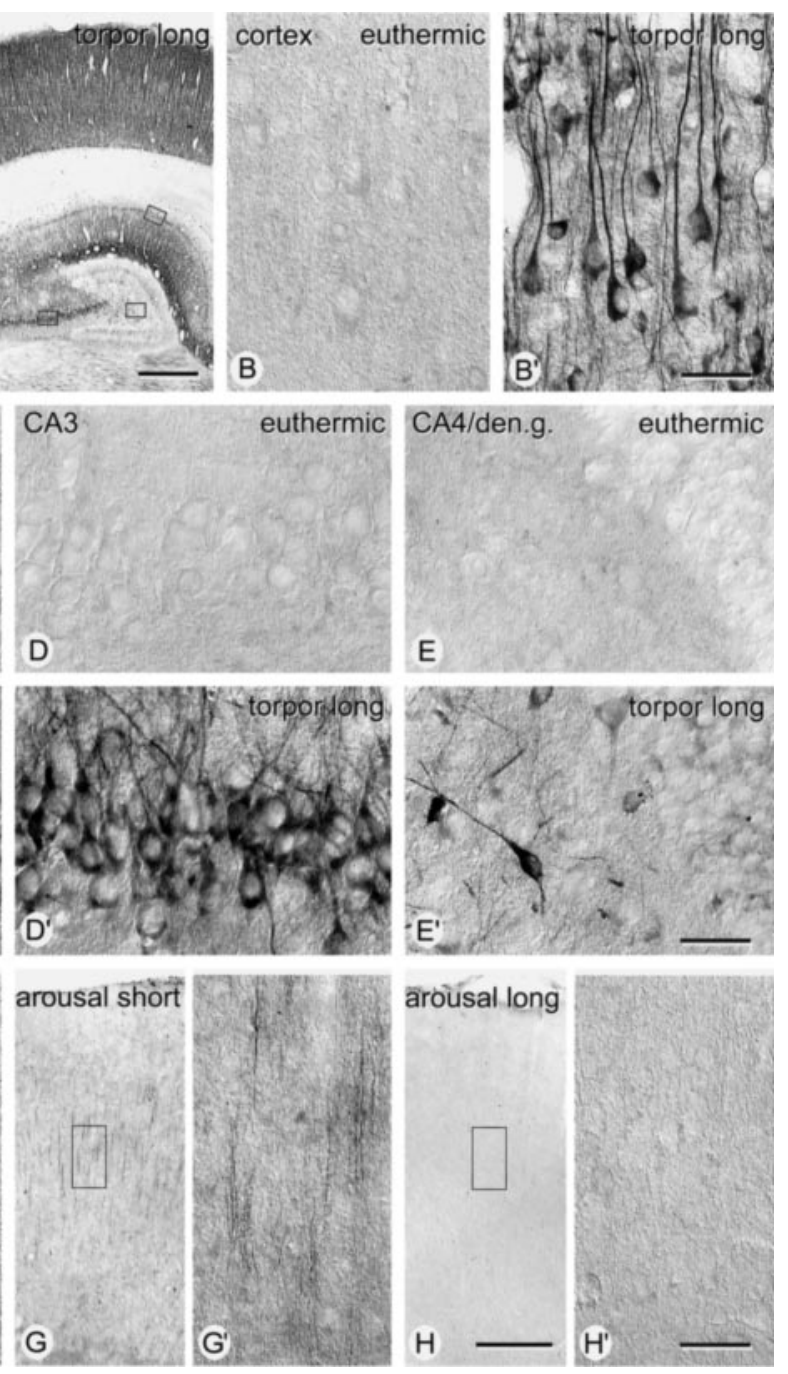

euthermic

Figure 6. Distribution of immunohistochemically detectable PHF-like phosphorylated tau (AT8) in the hippocampus during hibernation. $A$, Euthermic animal; insets are shown at higher magnification in $B-E ; A^{\prime}$, Animal in long torpor (TL); insets are shown at higher magnification in $B^{\prime}-E^{\prime}$. $F-H$, Neocortex (corresponding to the area shown in $B, B^{\prime}$ ) in animals shortly after beginning of torpor $\left(\mathrm{TS} ; F, F^{\prime}\right)$, shortly after arousal $\left(A S ; G, G^{\prime}\right)$, and after longer arousal period $\left(A L ; H, H^{\prime}\right) . F^{\prime}-H^{\prime}$ correspond to insets in $F-H$. Scale bars: $A, A^{\prime}, 500 \mu \mathrm{m} ; B-E, B^{\prime}-H^{\prime}, 30 \mu \mathrm{m} ; F-H, 200 \mu \mathrm{m}$. regression during torpor and subsequent reinnervation in phases of arousal has been particularly well characterized for synaptic contacts between mossy fibers and hippocampal pyramidal neurons in ground squirrels (Popov and Bocharova, 1992; Popov et al., 1992; Hut et al., 2001).

We have been able to confirm and extend these studies on cyclic changes of the CA3 pyramidal cell afferentation by mossy fibers that are associated with changes in PSA-NCAM expression. PSA-NCAM is the developmentally regulated polysialylated form of the neural cell adhesion molecule NCAM, a cell surface glycoprotein that is involved in neuronal migration and neurite outgrowth (Seki and Arai, 1993; Cremer et al., 1997). In the adult rodent brain, expression of PSA-NCAM is restricted to brain areas that retain a high neuroplastic potential, such as the hippocampus and olfactory areas, where it might fulfill an instructive function in brain plasticity (Seki and Arai, 1993, 1999; Durbec and Cremer, 2001). PSA-NCAM expression is related to bouton formation and remodeling, which accompany synapse formation (Seki and Arai, 1999), a process of critical importance for hippocampal plasticity in learning and memory (Fox et al., 1995; Muller et al., 1996; Murphy et al., 1996) and, as shown in the present study, for re-establishing neuronal connectivity during arousal.

One cellular mechanism that contributes to the regulated suppression of metabolism and thermogenesis during hibernation is reversible phosphorylation of enzymes and proteins that limits rates of flux through metabolic pathways (Storey 1987, 1997; Mehrani and Storey, 1997; 
MacDonald and Storey, 1998, 1999; Chen et al., 2001). Reversible phosphorylation during hibernation also affects synaptic membrane proteins (Shchipakina et al., 1995), a process known to be involved in synaptic plasticity (Walaas and Greengard, 1991). Here we demonstrate that this mechanism of reversible protein phosphorylation also affects the microtubuleassociated protein tau, thereby generating a condition that in the adult human brain is associated with neurofibrillary degeneration.

One remarkable feature is the apparent high molecular weight of tau extracted from euthermic animals ranging from 68 to $72 \mathrm{kDa}$, which is even shifted in the torpor animals. This slow electrophoretic mobility is reminiscent of PHF-tau and not present in biopsy-derived human tau or freshly prepared rodent tau. The retarded electrophoretic mobility in the euthermic and torpor state is solely attributable to tau phosphorylation, because dephosphorylation shifts tau from 72 to 63 $\mathrm{kDa}$. A likely explanation is the presence of two additional potential phosphorylation sites in ground squirrel compared with human.

A high phosphorylation of tau at some PHF-like epitopes, e.g., at Ser-202, is also seen during normal development of the mammalian (Goedert et al., 1993) and non-mammalian (Rösner et al., 1994) brain, where it is downregulated during maturation. In the human brain, the switch from the highly phosphorylated to the less phosphorylated state occurs around birth (Goedert et al., 1993) and, thus, coincides with synaptogenesis, which is similar to what is seen in the present paradigm. The developmental regulation of tau, however, extends to the level of alternative mRNA splicing, giving rise to different isoform pattern. In fetal human brain there is a single isoform, but in adult brain there are six isoforms (Goedert et al., 1989a,b). At variance with this developmental shift of mRNA splicing, the pattern of six isoforms seen in the brain of adult ground squirrels was not affected by the hibernation cycle.

The present results, thus, indicate that regulating tau(hyper)phosphorylation is preserved in the adult mammalian brain as a naturally occurring process associated with specific requirements on neuroprotection and plasticity. It apparently reflects a physiological mechanism and is not necessarily associated with pathological effects. The necessity, however, of regular arousal phases to protect against permanent memory loss might indicate the potentially deleterious sequelae of this process if it lasts too long. The present results, thus, support the suggestion that hyperphosphorylation of tau reflects a protective mechanism in a unfavorable environment (Ihara, 2001). Recent studies investigating tau phosphorylation in relation to neuronal suscep-

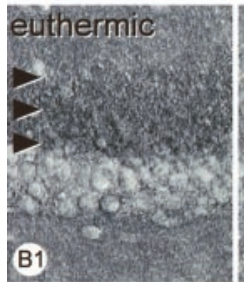

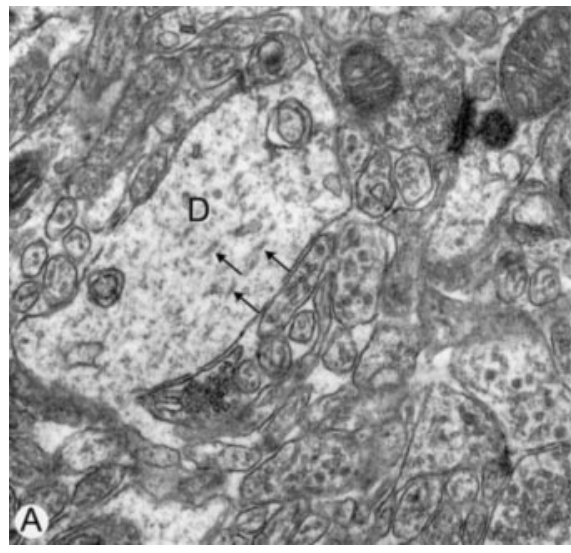

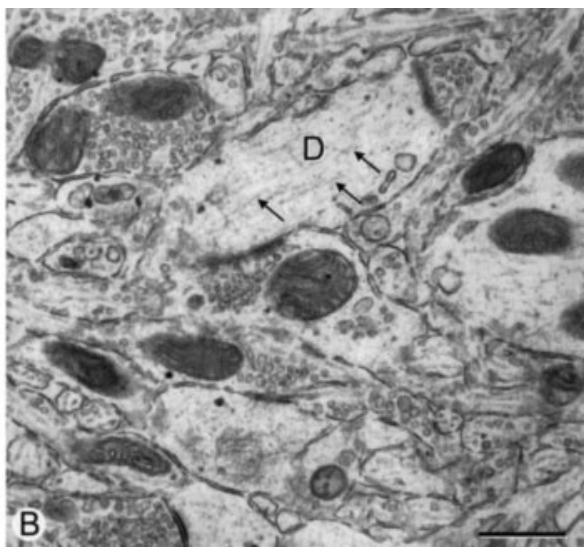

Figure 7. Electron micrographs demonstrating longitudinally sectioned dendritic profiles $(D)$ in the neocortex of an euthermic animal $(A)$ and during long torpor $(B)$. Arrows indicate microtubules. There are no indications for the formation of neurofibrillary aggregations. Scale bar, $0.5 \mu \mathrm{m}$.
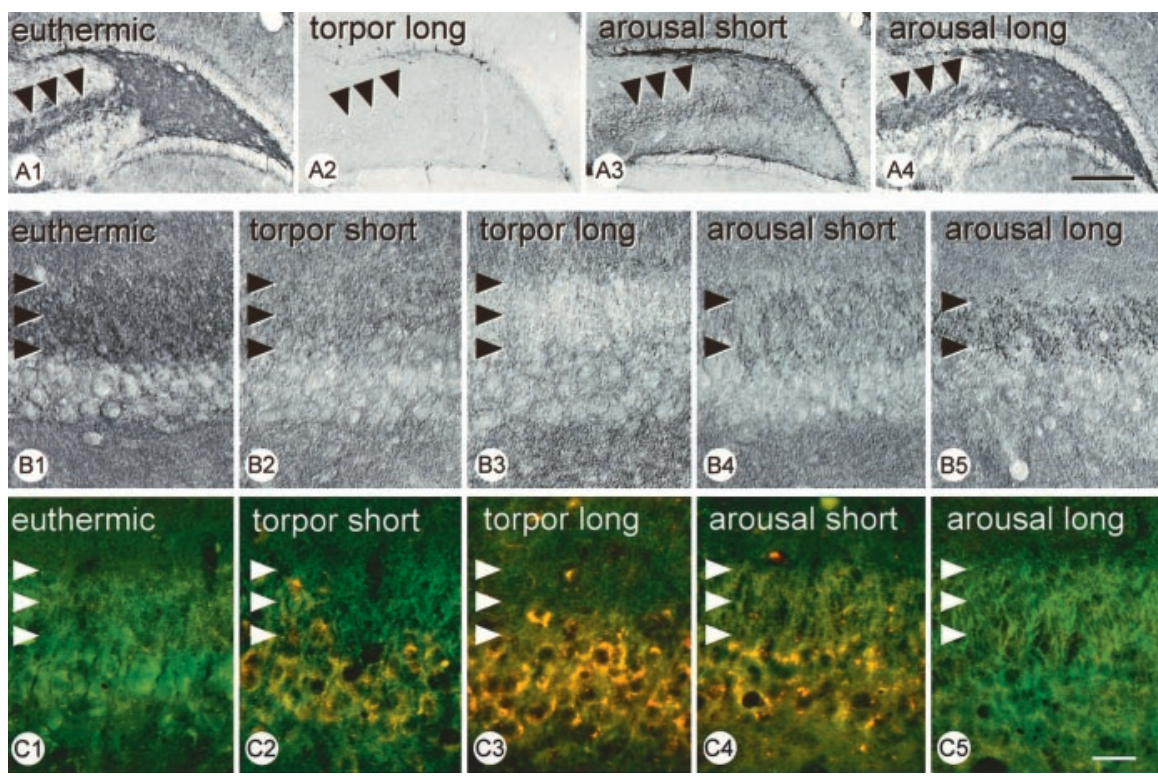

Figure 8. Cyclic changes in the hippocampal mossy fiber system during hibernation. A1-A4, Mossy fibers labeled by PSA NCAM (arrowheads). Note the disappearance of staining during torpor and its progressive reappearance during arousal. B1-B5, Immunohistochemical reaction for synaptophysin in the stratum lucidum (arrowheads). Reactivity decreases and increases again AT8 (red), coexpression in yellow. Although MAP2 reactivity in the stratum lucidum (arrowheads) disappears in torpor and reappears during arousal with a similar time course as PSA-NCAM $(A)$ and synaptophysin $(B)$, an inverse pattern is observed for AT8 reactivity in corresponding pyramidal cell bodies. Scale bars: $A, 300 \mu \mathrm{m} ; B, C, 50 \mu \mathrm{m}$.

tibility for apoptosis have indeed suggested that a modest increase in tau phosphorylation correlates with increased protection of neurons against cell death (Lesort et al., 1997; Nagy and Esiri, 1997; Arendt et al., 1998b; Esclaire et al., 1998; Mills et al., 1998; Yardin et al., 1998).

By hibernation, animals may save up to $90 \%$ of the energy that would otherwise be required (Geiser, 1988; Wang, 1989; Heldmaier and Ruf, 1992; McKee and Andrews, 1992). In torpor, when the phosphorylation stage of tau is highest, the metabolic rate is strongly suppressed, often to $<5 \%$ of the normal euthermic rate. This situation reflects a "vita minima", where energy supply and requirements are both low but still balanced. Homeostatic control is preserved and brain damage does not occur. Hibernation is, therefore, associated with tolerance to deprivation of oxygen and glucose (Frerichs and Hallenbeck, 1998). In this 


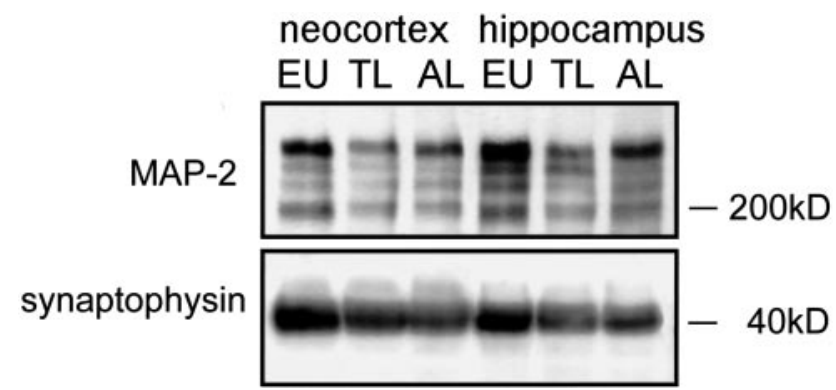

Figure 9. Immunoblots for MAP2 and synaptophysin from extracts of the neocortex and hippocampus in an euthermic animal (EU), in long torpor (TL), and after long arousal (AL).

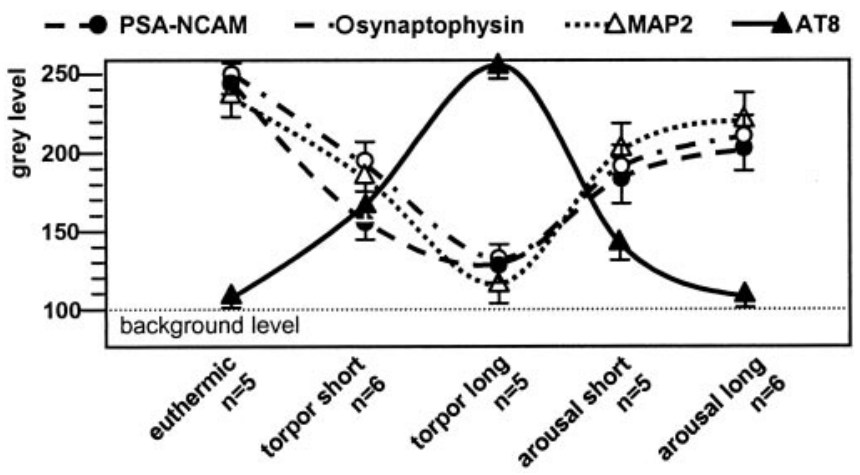

Figure 10. Synopsis of cyclic changes in the hippocampal mossy fiber system and CA3 target neurons during hibernation obtained by densitometrical analysis on immunohistochemical preparations, processed in parallel. An inverse cyclic relationship is observed between presynaptic markers (PSA-NCAM, synaptophysin) and postsynaptic markers (MAP2) in the stratum lucidum on one side and PHF-like tau (AT8) in somata of CA3 pyramidal neurons on the other side.

way, hibernation is different from starvation or energy deprivation previously shown to be associated with tau hyperphosphorylation (Yanagisawa et al., 1999; Planel et al., 2001). The latter reflects a mismatch between energy supply and requirement, which eventually induces cell damage.

Neuroprotective mechanisms that permit hibernating animals to tolerate severe reductions in cerebral blood flow and oxygen delivery capacity seem to involve increased phosphorylation of the eukaryotic elongation factor-2 (eEF-2) (Chen et al., 2001). This eEF-2 phosphorylation might represent a specific mechanism for inhibition of the elongation phase of protein synthesis (Frerichs et al., 1998) and is related to the activity of protein phosphatase 2A (PP2A) that is downregulated during hibernation (Chen et al., 2001). Inhibition of PP2A, the most abundant Ser/Thr phosphatase in the brain, which also regulates the phosphorylation stage of tau (Drewes et al., 1992; Goedert et al., 1992a,b; Gong et al., 1994), might, thus, be involved in a neuroprotective program. This potentially neuroprotective function of downregulating PP2A is in agreement with our previous study on in vivo inhibition of PP2A (Arendt et al. 1998b). After chronic inhibition of PP2A, PHF-like tau phosphorylation was induced in the hippocampus where it followed a similar pattern of cellular distribution (CA3 $>$ CA1 $>$ dentate gyrus) as in the present study during hibernation. Neurons that contained high amounts of PHF-like tau, moreover, were protected against apoptosis. The downregulation of PP2A after starvation, associated with tau hyperphosphorylation (Planel et al., 2001), might similarly reflect the induction of an active neuroprotective program against effects of failing energy supply (Weinbrenner et al., 1998; Armstrong and Ganote, 1992).
Hyperphosphorylation might confer tau resistance to proteases and could, thus, be a mechanism to stabilize its structure. Stabilization of cytoskeletal proteins might be a mechanism to "freeze" the dynamic structure during a "vita minima", preventing its degradation and preserve it for rapid activation in arousal phases. If synaptic connectivity is compromised during torpor and re-established very quickly in a similar way as before, a mechanism must exist that "marks" those sites that will be occupied by synapses again. This mechanism might potentially involve stabilized cytoskeletal proteins and need to be particularly well developed in neurons with a high neuroplastic potential. This would explain the hierarchy of neuronal vulnerability against neurofibrillary degeneration that has previously been shown to follow the pattern of the neuroplastic potential in the adult brain (Arendt et al., 1998a).

Most importantly, PHF-like phosphorylation of tau in the present model is fully reversible through a mechanism that operates naturally in the mammalian brain. This paradigm might, thus, be useful to study the physiological regulation of tau phosphorylation and dephosphorylation critically involved in the process of neurofibrillary degeneration in $\mathrm{AD}$ and related conditions.

\section{References}

Alexander L (1934) The neurofibrils in systemic disease and in supravital experiments, with remarks on pseudo-atrophy of the brain. Arch Neurol Psychiatry 32:933-962.

Arendt T, Brückner MK, Gertz HJ, Marcova L (1998a) Cortical distribution of neurofibrillary tangles in Alzheimer's disease matches the pattern of neurones that retain their capacity of plastic remodelling in the adult brain. Neuroscience 83:991-1002.

Arendt T, Holzer M, Fruth R, Brückner MK, Gärtner U (1998b) Phosphorylation of tau, $\mathrm{A} \beta$-formation, and apoptosis after in vivo inhibition of PP-1 and PP-2A. Neurobiol Aging 19:3-13.

Armstrong SC, Ganote CE (1992) Effects of protein phosphatase inhibitors okadaic acid and calyculin A on metabolically inhibited and ischaemic isolated myocytes. J Mol Cell Cardiol 24:869-884.

Ashford JW, Jarvik L (1985) Alzheimer's disease: does neuron plasticity predispose to axonal neurofibrillary degeneration? $\mathrm{N}$ Engl J Med 313:388-389.

Balli R (1906) Lesioni del reticolo neurofibrillare endocellulare in mammiferi adulti totalmente o parzialmente privati dell'apparecchio tiroparatiroideo e loro rapporto colla temperatura. Riv sper di freniat 32:803-812.

Braak H, Braak E (1991) Neuropathological staging of Alzheimer related changes. Acta Neuropathol 82:239-259.

Chen Y, Matsushita M, Nairn AC, Damuni Z, Cai D, Frerichs KU, Hallenbeck JM (2001) Mechanisms for increased levels of phosphorylation of elongation factor-2 during hibernation in ground squirrels. Biochemistry 40:11565-11570.

Cotman CW, Anderson KJ (1988) Synaptic plasticity and functional stabilization in the hippocampal formation: possible role in Alzheimer's disease. Adv Neurol 47:313-335.

Cremer H, Chazal G, Goridis C, Represa A (1997) NCAM is essential for axonal growth and fasciculation in the hippocampus. Mol Cell Neurosci 8:323-335.

Daan S, Barnes BM, Strijkstra AM (1991) Warming up for sleep? Ground squirrels sleep during arousals from hibernation. Neurosci Lett 128:265-268.

Donaggio A (1906) Effetti dell'azione combinata del digiuno e del freddo sui centri nervosi di mammiferi adulti. Riv sper di freniat 32:373-393.

Drewes G, Lichtenberg-Kraag B, Doring F, Mandelkow EM, Biernat J, Goris J, Doree M, Mandelkow E (1992) Mitogen activated protein (Map) kinase transforms tau-protein into an Alzheimer-like state. EMBO J 11:2131-2138.

Durbec P, Cremer H (2001) Revisiting the function of PSA-NCAM in the nervous system. Mol Neurobiol 24:53-64.

Esclaire F, Terro F, Yardin C, Hugon J (1998) Neuronal apoptosis is associated with a decrease in tau mRNA expression. NeuroReport 9:1173-1177. 
Flood DG, Coleman PD (1990) Hippocampal plasticity in normal aging and decreased plasticity in Alzheimer's disease. Prog Brain Res 83:435-443.

Fox GB, O'Connell AW, Murphy KJ, Regan CM (1995) Memory consolidation induces a transient and time-dependent increase in the frequency of neural cell adhesion molecule polysialylated cells in the adult rat hippocampus. J Neurochem 65:2796-2799.

French A (1985) Allometries of the durations of torpid and euthermic intervals during mammalian hibernation: a test of theory of metabolic control of the timing of changes in body temperature. J Comp Physiol [B] 156:13-19.

Frerichs KU, Hallenbeck JM (1998) Hibernation in ground squirrels induces state and species-specific tolerance to hypoxia and aglycemia: an in vitro study in hippocampal slices. J Cereb Blood Flow Metab 18:168-175.

Frerichs KU, Smith CB, Brenner M, DeGracia DJ, Krause GS, Marrone L, Dever TE, Hallenbeck JM (1998) Suppression of protein synthesis in brain during hibernation involves inhibition of protein initiation and elongation. Proc Natl Acad Sci USA 95:14511-14516.

Gabriel A, Klussmann FW, Igelmund P (1998) Rapid temperature changes induce adenosine-mediated depression of synaptic transmission in hippocampal slices from rats (non-hibernators.). Neuroscience 86:67-77.

Geddes JW, Cotman CW (1991) Plasticity in Alzheimer's disease: too much or not enough? Neurobiol Aging 12:330-333.

Geiser F (1988) Reduction of metabolism during hibernation and daily torpor in mammals and birds: temperature effect or physiological inhibition? J Comp Physiol [B] 158:25-37.

Geiser F, Kenagy GJ (1988) Torpor duration in relation to temperature and metabolisms in hibernating ground squirrels. Physiol Zool 61:442-449.

Goedert M, Spillantini MG, Jakes R, Rutherford D, Crowther RA (1989a) Multiple isoforms of human microtubule-associated protein tau: sequences and localization in neurofibrillary tangles of Alzheimer's disease. Neuron 3:519-526.

Goedert M, Spillantini MG, Potier MC, Ulrich J, Crowther RA (1989b) Cloning and sequencing of the cDNA encoding an isoform of microtubule-associated protein tau containing four tandem repeats: differential expression of tau protein mRNAs in human brain. EMBO J 8:393-399.

Goedert M, Cohen ES, Jakes R, Cohen P (1992a) P42 Map kinase phosphorylation sites in microtubule-associated protein tau are dephosphorylated by protein phosphatase-2A1: implications for Alzheimer's disease. FEBS Lett 312:95-99.

Goedert M, Spillantini MG, Cairns NJ, Crowther RA (1992b) Tau proteins of Alzheimer paired helical filaments: abnormal phosphorylation of all six brain isoforms. Neuron 8:159-168.

Goedert M, Jakes R, Crowther RA, Six J, Lubke U, Vandermeeren M, Cras P, Trojanowski JQ, Lee VM (1993) The abnormal phosphorylation of tau protein at Ser-202 in Alzheimer disease recapitulates phosphorylation during development. Proc Natl Acad Sci USA 90:5066-5070.

Gong CX, Grundke-Iqbal I, Iqbal K (1994) Dephosphorylation of Alzheimer's disease abnormally phosphorylated-tau by protein phosphatase2A. Neuroscience 61:765-772.

Härtig W, Brückner G, Holzer M, Brauer K, Bigl V (1995) Digoxigenylated primary antibodies for sensitive dual-peroxidase labelling of neural markers. Histochem Cell Biol 104:467-472.

Heldmaier G, Ruf T (1992) Body temperature and metabolic rate during natural hypothermia in endotherms. J Comp Physiol [B] 162:696-706.

Hut RA, de Wilde MC, Strijkstra AM, Van der Zee EA, Daan S (2001) Neuronal changes in the hippocampus and $\mathrm{SCN}$ of hibernating ground squirrels. Soc Neurosci Abstr 27:535.11.

Hut RA, Barnes BM, Daan S (2002a) Body temperature patterns before, during, and after semi-natural hibernation in the European ground squirrel. J Comp Physiol [B] 172:47-58.

Hut RA, Van der Zee EA, Jansen K, Gerkema MP, Daan S (2002b) Gradual reappearance of post-hibernation circadian rhythmicity correlates with numbers of vasopressin-containing neurons in the suprachiasmatic nuclei of European ground squirrels. J Comp Physiol [B] 172:59-70.

Ihara Y (2001) PHF and PHF-like fibrils: cause or consequence? Neurobiol Aging 22:123-126.

Kalmijn S, Mehta KM, Pols HA, Hofman A, Drexhage HA, Breteler MM (2000) Subclinical hyperthyroidism and the risk of dementia. The Rotterdam study. Clin Endocrinol 53:733-737.

Kavanau JL (1997) Memory, sleep and the evolution of mechanisms of synaptic efficacy maintenance. Neuroscience 79:7-44.
Kenagy GJ, Sharbaugh SM, Nagy KA (1989) Annual cycle of energy and time expenditure in a Golden mantled ground squirrel population. Oecologia 78:269-282.

Krilowicz BL, Glotzbach SF, Heller HC (1988) Neuronal activity during sleep and complete bouts of hibernation. Am J Physiol 255:R1008-R1019.

Lesort M, Blanchard C, Yardin C, Esclaire F, Hugon J (1997) Cultured neurons expressing phosphorylated tau are more resistant to apoptosis induced by NMDA or serum deprivation. Mol Brain Res 45:127-132.

Lewy FH (1923) Die Lehre von Tonus und der Bewegung. In: Monographien aus dem Gesamtgebiet der Neurologie und Psychiatrie (Alzheimer A, Lewandowski, M, eds), p 34. Berlin: Springer.

MacDonald JA, Storey B (1998) cAMP-dependent protein kinase from brown adipose tissue: temperature effects on kinetic properties and enzyme role in hibernating ground squirrels. J Comp Physiol [B] 168:513-525.

MacDonald JA, Storey B (1999) Regulation of ground squirrel $\mathrm{Na}^{+} \mathrm{K}^{+}$ATPase activity by reversible phosphorylation during hibernation. Biochem Biophys Res Commun 254:424-429.

McKee G, Andrews JF (1992) The costs and savings of hibernation in the golden hamster. J Physiol (Lond) 446:451.

Malinsky J (1983) Quantitative analysis of morphological changes in the spinal cord of the hibernating bat. Folia Morphologica 31:40-45.

Malinsky J, Malinska J (1975) Changes of the motoneurons and synapses of the spinal cord of the hedgehog during hibernation. Proceedings of the Xth International Congress of Anatomists, Tokyo, Japan.

Malinsky J, Malinska J (1988) Ultrastructural changes of synapses in supraoptic nucleus of Hedgehog during Hibernation. Acta Universitatis Palackianae Olomucensis 12:117-125.

Malinsky J, Polach A (1985) Changes of synaptic apparatus in the brain cortex of the hedgehog during hibernation (a quantitative Golgi and electron microscopic study). Acta Universitatis Palackianae Olomucensis 108:109-115.

Mehrani H, Storey KB (1997) Protein kinase C from bat brain: the enzyme from a hibernating mammal. Neurochem Int 31:139-150.

Mesulam MM (1999) Neuroplasticity failure in Alzheimer's disease: bridging the gap between plaques and tangles. Neuron 24:521-529.

Millesi E, Prossinger H, Dittami JP, Fieder M (2001) Hibernation effects on memory in European ground squirrels (Spermophilus citellus). J Biol Rhythm 16:264-271.

Mills JC, Lee VMY, Pittman RN (1998) Activation of a PP2A-like phosphatase and dephosphorylation of $\tau$ protein characterize onset of the execution phase of apoptosis. J Cell Sci 111:625-636.

Muller D, Wang C, Skibo G, Toni N, Cremer H, Calaora V, Rougon G, Kiss JZ (1996) PSA-NCAM is required for activity-induced synaptic plasticity. Neuron 17:413-422.

Murphy JK, O'Connell W, Regan CM (1996) Repetitive and transient increases in hippocampal neural cell adhesion molecule polysialylation state following multitrial spatial training. J Neurochem 67:1268-1274.

Nagy Z, Esiri MM (1997) Apoptosis-related protein expression in the hippocampus in Alzheimer's disease. Neurobiol Aging 18:565-571.

Oklejewicz M, Daan S, Strijkstra AM (2001) Temporal organisation of hibernation in wild-type and tau mutant Syrian hamsters. J Comp Physiol [B] 171: 431:439.

Planel E, Yasutake K, Fujitas SC, Ishiguro K (2001) Inhibition of protein phosphatase $2 \mathrm{~A}$ overrides tau protein kinase I/glycogen synthase kinase $3 \beta$ and cyclin-dependent kinase 5 inhibition and results in tau hyperphosphorylation in the hippocampus of starved mouse. J Biol Chem 276:34298-34306.

Popov VI, Bocharova LS (1992) Hibernation-induced structural changes in synaptic contracts between mossy fibres and hippocampal neurons. Neuroscience 48:53-62.

Popov VL, Bocharova LS, Bragin AG (1992) Repeated changes of dendritic morphology in the hippocampus of ground squirrels in the course of hibernation. Neuroscience 48:45-51.

Ramón y Cajal S (1904) Variacones morfológicas, normales y pathológicas del reticulo neurofibrillar Trabajos del laborat de investig biol. de la Univ de Madrid 3:9-15.

Ramón y Cajal S (1928) Degeneration and regeneration of the nervous system. London: Oxford UP.

Rasdolsky J (1926) Histologische Veränderungen in dem zentralen und pe- 
ripherischen Nervensystem der Tiere mit exstirpierten Schild- und Nebenschilddrüsen. Z Neurol Psychiat 106:96-113.

Rösner H, Rebhan M, Vacu G, Vanmechelen E (1994) Expression of a paired helical filament tau epitope in embryonic chicken central nervous system. NeuroReport 5:1164-1166.

Seki T, Arai Y (1993) Distribution and possible roles of the highly polysialylated neural cell adhesion molecule (NCAM-H) in the developing and adult central nervous system. Neurosci Res 17:265-290.

Seki T, Arai Y (1999) Different polysialic acid-neural cell adhesion molecule expression patterns in distinct types of mossy fiber boutons in the adult hippocampus. J Comp Neurol 410:115-125.

Shchipakina T, Zharikova A, Arkhipov V (1995) Protein phosphorylation of synaptic membranes isolated from the brain of ground squirrels during hibernation. NeuroReport 7:278-280.

Stern K, Elliott KAC (1949) Experimental observation on the so-called senile changes of intracellular neurofibrils. Am J Psychiat 106:190-194.

Strijkstra AM, Daan S (1997) Sleep during arousal episodes as a function of prior torpor duration in hibernating European ground squirrels. J Sleep Res 6:36-43.

Strijkstra AM, Daan S (1998) Dissimilarity of slow-wave activity enhancement by torpor and sleep deprivation in a hibernator. Am J Physiol 275:R1110-R1117.

Strijkstra AM, Deboer T, Daan S (1999) Dynamics of cortical EEG power decrease rate during entry into natural hypothermia in European ground squirrels. In: Sleep-Wake Research in The Netherlands, Vol 10 (Van Bemmel AL, Beersma DGM, Folgering H, Hofman WF, Ruigt GSF, eds), pp 157-162. Utrecht, The Netherlands: Drukkerij Elinkwijk B.V.

Strijkstra AM, Hut RA, Stieler J, Van der Zee EA (2003) Hippocampal synaptophysin immunoreactivity is reduced during natural hypothermia in ground squirrels. Neurosci Lett 344:29-32.

Storey KB (1987) Regulation of liver metabolism by enzyme phosphorylation during mammalian hibernation. J Biol Chem 262:1670-1673.
Storey KB (1997) Metabolic regulation in mammalian hibernation: Enzyme and protein adaptations. Comp Biochem Physiol [A] 118:1115-1124.

Swaab DF (1991) Brain aging and Alzheimer's disease, "wear and tear" versus "use it or lose it". Neurobiol Aging 12:317-324.

Tello F (1904) Las neurofibrillas en los vertebrados inferiores. Trab lab invest biol Univ Madrid 3:113-151.

Thompson JD, Higgins DG, Gibson TJ (1994) CLUSTAL W: improving the sensitivity of progressive multiple sequence alignment through sequence weighting, position-specific gap penalties and weight matrix choice. Nucleic Acids Res 22:4673-4680.

Walaas SI, Greengard P (1991) Protein phosphorylation and neuronal function. Pharmacol Rev 43:299-349.

Walker JM, Glotzbach SF, Berger RJ, Heller HC (1977) Sleep and hibernation in ground squirrels: Electrophysiological observations. Am J Physiol 233:213-221.

Wang LCH (1978) Energetic and field aspects of mammalian torpor: the Richardson's ground squirrel. In: Strategies in cold: natural torpidity and thermogenesis. pp 109-145. New York: Academic.

Wang LCH (1989) Ecological, physiological and biochemical aspects of torpor in mammals and birds. In: Advances in comparative and environmental physiology, Vol 4, (Wang LCH, ed), pp361-401. Heidelberg: Springer.

Weinbrenner C, Baines CP, Liu GS, Armstrong SC, Ganote CE, Walsh AH, Honkanen RE, Cohen MV, Downey JM (1998) Fostriecin, an inhibitor of protein phosphatase $2 \mathrm{~A}$, limits myocardial infarct size even when administered after onset of ischemia. Circulation 98:899-905.

Yanagisawa M, Planel E, Ishiguro K, Fujita SC (1999) Starvation induces tau hyperphosphorylation in mouse brain: implications for Alzheimer's disease. FEBS Lett 461:329-333.

Yardin C, Terro F, Esclaire F, Rigaud M, Hugon J (1998) Brefeldin A-induced apoptosis is expressed in rat neurons with dephosphorylated tau protein. Neurosci Lett 250:1-4. 